\title{
Las representaciones de la criminalidad entre el comisariado cordobés
}

\author{
Criminal representations between chiefs officers in Córdoba
}

\author{
Natalia Sofía Castro nsofiacastro@gmail.com \\ https://orcid.org/0000-0003-0175-4739
}

Instituto Académico Pedagógico de Ciencias Sociales; Universidad Nacional de Villa María

$$
\text { (Argentina) }
$$

\section{Resumen}

Los estudios en torno a la seguridad y la institución policial, ganan en riqueza cuando se intenta comprender la voz de sus agentes. Partiendo de esta concepción, presentamos una parte de un Trabajo final de grado para la licenciatura en Sociología, en el que se pretende discernir las representaciones de un grupo de oficiales jefes (comisarios y subcomisarios) de la Policía de Córdoba en relación a la criminalidad y el delito. 
Para esta investigación, se utilizó una metodología cualitativa, basada en entrevistas exploratorias. Evaluamos el producto de las entrevistas en sus supuestos compartidos con distintas corrientes criminológicas para explorar regularidades y excepcionalidades entre ellas.

Palabras clave: Policía; criminalidad; criminología; representaciones; oficiales jefe.

Abstract

Studies concerning security and Police forces are enhanced when we try to understand them from the voice of the agents who belong to the Institution.

This is the guiding principle of the Graduate Thesis for the Bachelor's Degree in Sociology we are presenting. This part of the dissertation aims at gaining insight into the representations of a group of chief officers (chiefs commissioners and sub commissioners) related to crime and criminal offence.

This is a qualitative research based on a series of exploratory interviews. The gathered statements were evaluated in the light of the shared presumptions respect to different criminal trends in order to explore the regularities and exceptionalities among them.

Keywords: Police; crime; criminology; representations; chief officers.

Las tensiones y los infinitos matices que existen para pensar la gestión de la seguridad se encuentran en constante crecimiento y complejización. Los clamores por aplicar "mano dura" y restaurar un orden, chocan y se funden entre aquellas voces que sugieren una gestión de la seguridad más democrática y ciudadana (Kessler, 2011; Sozzo, 1999). Como indica Brodeur (2011) tanto la criminalidad, como la acción policial se muestran a través de una puesta en escena dramática que, más que revelarla, la disfraza.

En estos escenarios, las ciencias sociales, y en particular, la sociología, ofrecen herramientas clave para comprender a la institución policial y las prácticas de los/as agentes que en su interior se desenvuelven. La divulgación de lo encontrado en trabajos de campo, se vuelve vital para enriquecer el conocimiento científico, las reflexiones teóricas y críticas acerca de la institución, su lugar en la gestión de la seguridad y las formas en que se entiende la criminalidad dentro y fuera de ella.

El presente informe resume uno de los objetivos de mi Trabajo Final de Grado para la Licenciatura en Sociología de la Universidad Nacional de Villa María, dirigido por la Magister 
Mariana Carbajo y codirigido por el Doctor Agustín Zanotti. Este objetivo es dar cuenta de las representaciones, las visiones de mundo presentes entre un grupo de oficiales jefes comisarios y subcomisarios- de la Policía de Córdoba, en relación al delito y la criminalidad. Entendemos que la importancia del mismo está dada por la necesidad y la inminencia de modificaciones en las formas de gestionar el control y prevención del delito, particularmente desde las políticas públicas, pero también desde la articulación de diversos actores con la institución policial y sus agentes.

Vale aclarar, que se aprecian los sentidos que los/as entrevistados/as tienen sobre el delito desde un punto de vista etiológico, ya que al ser consultados/as sobre los delitos más recurrentes en la ciudad o su zona de trabajo, qué delitos suelen detectar, cómo consideran que está la inseguridad en su zona, fue usual que recurran a hablar sobre las causas del delito. Sin embargo, por detrás de estas acepciones encontramos que existe una disputa en torno a los sentidos sobre qué es el delito, y cuál es el lugar de la policía en su gestión.

En este sentido, creemos que las formas de estudiar el fenómeno criminal no están desligadas de las representaciones y visiones del mundo que existen en torno a las relaciones sociales y el papel que juega la conflictividad en las mismas. Así, estudiaremos algunas corrientes criminológicas que sirven de modelos para entender mejor algunas manifestaciones.

Estas criminologías son más bien una serie de características compartidas que explican las dinámicas del cambio y los principios estratégicos que subyacen (Garland, 2001: 15). Se pretende indagar exploratoriamente, por los supuestos presentes en sus apreciaciones en torno al crimen, y los elementos en común que guardan con formas de entender la criminalidad. La clasificación de las criminologías presentadas, nos ha ayudado por un lado a un mayor entendimiento de los supuestos detrás las diversas formas de comprender la criminalidad. Por otro, nos sirvió a fines analíticos, para explorar algunas regularidades y preeminencias en lo discursos y las prácticas discursivas de los oficiales jefes entrevistados/as.

Así, el trabajo está divido en cinco apartados. En el primero se presentará un resumen de los aportes teóricos y metodológicos que son base del trabajo. Luego mostramos las apreciaciones de los/as oficiales jefes entrevistados/as en torno al delito. Para esto, en un principio rescatamos aquellas que comparten supuestos con las criminologías del otro, este orden responde a la gran preeminencia encontrada en el trabajo de campo de esta forma de representar la criminalidad. Siguiendo el orden, y en cercana articulación con el apartado mencionado, ubicamos las explicaciones del delito que mostraron elementos compartidos con las teorías del underclass (infraclase). Seguidamente, exploramos aquellas concepciones que se vinculan a las formas de entender la criminalidad desde las criminologías de la vida cotidiana, o criminologías del sí mismo. Por último, rescatamos las pocas alusiones que se han 
hecho en relación a formas más garantistas de pensar el fenómeno en cuestión, que Garland las ubica como criminología propia del complejo penal welfare (1).

Estas criminologías, a los fines del informe, nos orientan como modelos para pensar distintas formas de concebir la criminalidad, las explicaciones de su existencia, sus motivos y orígenes. Sin embargo, resaltamos que los discursos exceden los modelos, en las entrevistas encontramos, más bien, distintos matices que se mueven entre las criminologías que nos acerca el autor.

\section{Consideraciones teóricas y metodológicas}

En relación a la policía, concebimos, como indica Galvani (2016), que estos también son trabajadores y tienen más en común con otros grupos sociales de lo que, como investigadores, estamos dispuestos a aceptar, especialmente cuando esa semejanza nos remite a sectores de bajos ingresos. En línea con estas afirmaciones Frederic (2009) nos ayuda a ver cómo la policía frecuentemente funciona como uno de esos lugares donde la sociedad se oculta a sí misma, oculta lo peor de sí. La autora nos muestra cómo se recarga sobre la policía todas las categorías socialmente construidas; sus mandatos sociales y públicos, sus estereotipos, discriminaciones, prejuicios, etcétera. En este trabajo, tomamos la propuesta formulada por la antropóloga, de construir una nueva manera de mirar a la policía, partiendo de una sociología de los usos de la fuerza pública, que haga el esfuerzo por deconstruir prejuicios y prenociones. En múltiples ocasiones, Bourdieu aclara que la sociología debe tomar como objeto, en lugar de caer en ella, la lucha por el monopolio de la representación legítima del mundo social (Bourdieu, 1990: 49). Nos recuerda, a partir de su teoría de las prácticas, que los objetos de conocimiento son construidos y no pasivamente registrados (Bourdieu, 2015). En razón de ello, en este trabajo en particular, tomamos la categoría de representación, para entender los diferentes puntos de vista y construcción de visiones de mundo de los/as policías cordobeses. La representación, según este autor, es entendida como una forma de construcción de visiones de mundo que se intentan imponer mediante luchas simbólicas. Al mismo tiempo, explica que los esquemas de percepción y de apreciación que funcionan en un momento dado, son producto de luchas simbólicas anteriores, y expresan el estado de las relaciones de fuerza simbólicas (Bourdieu 1990: 210). Pero a su vez, estas también son producto de la incorporación de las estructuras objetivas en las que los/as agentes están insertos (Bourdieu, 2015).

Question, Vol. 1, N. ${ }^{\circ} 63$, julio-septiembre 2019. ISSN 1669-6581

Instituto de Investigaciones en Comunicación | Facultad de Periodismo y Comunicación Social | Universidad Nacional de La Plata La Plata | Buenos Aires | Argentina

Página 4 de 19 
Bourdieu nos ayuda a entender los peligros de buscar representaciones a partir de los discursos o entrevistas. Advierte, en clave teórico metodológica, que los/as agentes tienen una "vivencia" que no es la verdad completa de lo que hacen y que, sin embargo, forma parte de la verdad de su práctica (Bourdieu, 1990: 71). Por ende la representación explícita o la expresión verbal, no alcanza lo esencial de la experiencia del mundo social, sino que el trabajo de construcción que esta experiencia implica se opera en la práctica (Bourdieu, 1990: 211). No obstante, nos recuerda que "La representación subjetiva del mundo social como legítimo forma parte de la verdad completa de este mundo" (Bourdieu, 1990: 66), por tanto no hay que dejar de lado la labor de recuperar las representaciones como objeto de estudio.

Haciendo una salvedad de tipo metodológica, nos interesa resaltar que para la puesta en práctica y el análisis de las entrevistas adoptamos la conciliación que hace Suárez de Garay (2016) de la teoría de la acción de Bourdieu con los discursos dentro de la policía. La antropóloga parte de entender a las expresiones de la experiencia del actor -como agente de cambio y unidad de análisis- como elementales para comprender la desigualdad y diferencia del mundo policial. En esta línea, recordamos que tomar el punto de vista del actor implica aceptar que el producto de este tipo de análisis será siempre una interpretación (del entrevistador) de otra interpretación (del informante). Por ende, hay que asumir que, aunque se trate de sujetos dentro de una misma institución, también poseen saberes diferenciales, conflictivos y hasta antagónicos (Suárez de Garay, 2016).

La perspectiva metodológica adoptada es cualitativa y la toma de datos se ha hecho durante los años 2016 y 2017. Partiendo de aquí, se buscará en los discursos, la forma en que este sector de la policía dota de sentido y presentan sus prácticas. Pretendemos dilucidar brevemente la diversidad de percepciones halladas en relación a los objetivos planteados, pero sin desmerecer, la presencia de algunas regularidades en sus relatos.

El universo de estudio está compuesto por la Policía de Córdoba, desde el cual se recorta a los/as oficiales jefes de la institución, es decir, los comisarios y subcomisarios, en términos de jerarquías. La técnica de recolección de datos ha sido el análisis de documentos, y la realización de entrevistas semi estructuradas a actores claves involucrados en la institución policial.

Como el presente pretende ser un estudio exploratorio, logrado a partir de un primer acercamiento al campo, se realizaron 11 entrevistas, el proceso de trabajo de campo se detuvo a partir de la saturación de categorías. La totalidad de los entrevistados pasaron entre 17 y 25 años dentro de la institución policial. Los/as entrevistados/as serán denominados con grado pseudónimos para cuidad su identidad, con este mismo fin, sólo especificamos el grado 
jerárquico que ocupan pero no identificaremos la dirección en la que trabajan dentro de la institución.

\section{Olor a delito}

Los primeros extractos de entrevista que resaltamos, tienen relación con una forma de explicar la criminalidad desde la otredad, pensando al delincuente como un otro peligroso e identificable a partir de una serie de características que comparten. En el transcurso del trabajo de campo, hemos encontrado una preeminencia de estas explicaciones ante la problemática de la delincuencia entre los/as entrevistados/as. Hallamos que estas representaciones comparten algunos supuestos con aquellos propios de las criminologías del otro.

Según Garland (2001), esta criminología se basa en formas de explicar el delito que desde una retórica que trata a los delincuentes como especies diferentes de individuos, como personas violentas y amenazadoras por quienes no podemos tener simpatía y a quienes no se puede ayudar. Aparece la idea de la irreversibilidad de su condición, esto último articulado íntimamente con los supuestos de las teorías del underclass, que desarrollaremos más adelante. En este caso, la esencialización de la diferencia -entre delincuentes y ciudadanos- se da, no sólo en base a la clase del sujeto a identificar, sino en base a aspectos estereotípicos, que incluyen pero exceden a la condición económica.

En primer lugar nos interesa resaltar el testimonio del subcomisario Raúl, quien explica desde su experiencia lo que significa el olfato policial, un término muy utilizado para describir el conocimiento práctico que guía el señalamiento de sujetos sospechosos.

"Nosotros tenemos, es una expresión medio vulgar, pero es el olfato policial, que se tiene, que sin ni siquiera haber... desde el policía más avezado y más eficiente, hasta el policía más vago y más desinteresado lo tiene. Porque es algo que te nace, porque vos a la persona que anda en algo raro, y apenas lo ves... a lo mejor no es sólo de la policía, pero te das cuenta más o menos, cómo habla un tipo, vos decís 'uh, este debe ser un... un estafador' o cosas por el estilo. Hay veces que a los tipos directamente los ves cómo viste, o los tatuajes que tienen, no hace falta tampoco ser un especialista en sociología para darte cuenta" (Raúl, subcomisario).

Esta explicación sobre el olfato policial sigue con la idea del delincuente como un sujeto identificable a través de estereotipos como la vestimenta, la forma de hablar o, en este caso en particular el subcomisario nombra la presencia de tatuajes. Destacamos este testimonio como 
una representación del saber policial que, en palabras de Bourdieu demuestra una representación mental, sobre la representación teatral que le dan los otros.

\begin{abstract}
las representaciones (mentales) que los diferentes grupos se hacen de las representaciones (teatrales) que dan (intencionalmente o no) los otros grupos, se presentan a la observación como sistemas de oposiciones que reproducen, acentuándolas y simplificándolas (a veces hasta la caricatura) las diferencias reales entre los estilos de vida, y que contribuyen a la vez a producir divisiones y a legitimarlas al hacerlas aparecer como fundadas desde la naturaleza (2015: 226).
\end{abstract}

En el caso que tomamos, no es sólo naturalizando las diferencias que el entrevistado fundamenta la división planteada. Sino desde el olfato que tiene el oficial jefe a partir de su relación práctica con el trabajo policial. Monjardet (2010) también se remite a este supuesto cuando explica el punto de vista "subjetivista" sobre el saber policial. En esta concepción, los saberes son incorporados a través de las cualidades personales de los agentes y su experiencia, valorizando el conocimiento adquirido en la calle, por sobre el adquirido en instancias de formación escolar.

El olfato policial es el que permite al subcomisario Raúl identificar sospechosos, pero también es el que permite a la comisario Daniela y al subcomisario Manuel, jactarse de ser "jueces naturales", o "sociólogos empíricos", capaces de sentenciar adecuadamente a sujetos sospechosos. En los testimonios que siguen, los/as entrevistados/as opinan sobre el cambio de de Código de Faltas a Código de Convivencia Ciudadana, que se dio en 2015 en la provincia. Creemos necesario resaltar que los testimonios que siguen no sólo demuestran distintos juicios respecto al código contravencional y sus modificaciones, sino que también nos acercan una forma de analizar y explicar la criminalidad, que es oportuno y apropiado resaltar en el presente capítulo.

"Si yo vivo en Villa Libertador y estoy en otro barrio, el policía te preguntaba y lo metían preso. No metían preso a cualquiera. Si pedís el documento y no te lo dan... Después también los cacos (2) se la sabían todas y te daban documentos falsos. Eso lo olfateás [...] Pusieron al ayudante fiscal cuando el juez natural, el único que puede juzgar esas cosas es la policía. Ahora las cosas cambiaron también por que los policías no leen el código. Tienen miedo de llevar gente. Se lo aplican a un estúpido que viene del trabajo. El 111 (3) es para todos, sólo se lo aplican a los cacos. Y me da bronca porque por ahí pasa el caco sin el casco y lo agarran, después pasa una maestra con la nena en una moto sin casco y no la agarran. Los 
delincuentes salen con los cascos ahora. Pero esa maestra que zafó les da clases a otros chicos después. Es un desastre" (Daniela, comisario).

"Al Código de Faltas había que hacerle unos toques sobre los derechos del aprehendido, con respecto a su capacidad para defenderse, porque muchas veces pasa que el policía, que es lo que yo denomino un sociólogo empírico, hace uso de su experiencia para clasificar si una persona es o no un delincuente. Y se puede equivocar, entonces ese contraventor debería tener más derechos a ejercer su defensa, pero hecha la ley hecha la trampa. El contraventor que conoce esas falencias ahora sale a hacer lo que se le canta las bolas en la calle" (Manuel, subcomisario).

En ambos relatos, podemos observar que el olfato aparece legitimado como medio para reconocer a posibles delincuentes, previo a la comisión de cualquier hecho, así como se ejemplifican casos en el que éstos utilizan tácticamente la legislación a su favor. Es el olfato el que le permite a la comisario Daniela saber quién es un caco y quién es una maestra, así como al subcomisario Manuel clasificar si una persona es o no delincuente. Estos aspectos se encuentran relacionados con la concepción del delincuente retratado como una alteridad amenazante, identificable a partir de aspectos estereotípicos.

No obstante no es sólo la apariencia el elemento que aparece en estos extractos para marcar estereotipos. La comisario Daniela trae a colación la dimensión territorial. No tener la dirección del documento en el barrio donde se encuentra una persona aparece en su relato como un aspecto que aporta al discernimiento de una persona como sospechosa.

Como indica Garland (2001: 300) la criminología del otro redramatiza al delincuente, y lo representa en términos melodramáticos, considerándolo una catástrofe, encuadrándolo en un lenguaje de guerra y la defensa social.

Estas representaciones señalan a los posibles delincuentes como sujetos exclusivamente a ser controlados, no necesariamente protegidos. Al contrario, en lugar de ser sujetos a los que hay que garantizarle seguridad, son retratados como amenazas que deben ser neutralizadas 0 eliminadas para el bien del resto de la sociedad. Estableciendo, así, una división que relega al sospechoso a una otredad. Siguiendo con este argumento, Kessler (2010) explica que existe en la región una construcción de los sectores populares, y en especial, los jóvenes de este sector, como alteridad en términos de peligrosidad, en tanto otras formas de discriminación (clase, etnia, nacionalidad, etcétera) ya no son habilitadas por la institucionalidad democrática. De este modo, "la alteridad amenazante se instituye como un criterio de separación legítimo, pues pareciera respetar el mandato democrático de no discriminar por ninguna de dichas 
variables, cuando en los hechos lo hace y a menudo por todas ellas al mismo tiempo" (Dimarco y Kessler, 2013: 227).

Crisafulli y Spósito (2011) destacan que la categoría de peligrosidad es propia de una retórica oficial, en la que los jóvenes de clases populares son rebajados a una categoría inferior a la de ciudadanos, remarcando una segregación entre éstos y los ciudadanos "decentes". Sumado al estigma de peligrosidad, los autores argumentan que estos agentes pasan a ser depositarios de la angustia social flotante.

Esto nos hace volver a tomar a Frederic (2011), quien señala que estas representaciones no son necesariamente inventadas por policías, sino que reflejan estereotipos y estigmas presentes en toda la sociedad. Como destaca Rodríguez Alzueta (2014), no hay olfato policial sin olfato social.

\section{De ahí no puede salir otra cosa}

Señalar a las condiciones de socialización como culpables del devenir delictual de los sujetos, y trazar un vínculo criminalidad-pobreza puede representarse a través de dos concepciones criminológicas principales. Por un lado, se puede vincular con un ideal rehabilitador y optimista, que plantea al trabajo y la educación como pilares defectuosos a fortalecer para revertir posibles escenarios de delincuencia. Pero entre los/as entrevistados/as, encontramos un predominio de otra forma de considerar esta asociación. Cuando el entorno de socialización se considera defectuoso, hay un punto en el cual se considera insalvable, y el contexto de pobreza pasa a ser pensado como irreversiblemente determinante de conductas delictuales. Estas formas de pensar la criminalidad son profundamente pesimistas respecto al ideal rehabilitador, pero también, de las posibilidades de las personas, y sobre todo los/as jóvenes de sectores populares.

Las concepciones que revisaremos en este apartado están cerca de teorías sobre el underclass (infraclase) y están íntimamente ligadas a las criminologías del otro. La concepción de los pobres como una underclass de excluidos, tal como lo expone Garland (2001) provee fuentes de legitimación para una política anti-welfare, en la que los pobres no merecen ser ayudados (2001: 16). Lejos de justificar políticas de bienestar, presentan una teoría que legitima el castigo a los pobres y el desarrollo de un Estado disciplinario. En esa óptica, las criminologías más cercanas a welfarismo-penal, parecen negar la responsabilidad individual del delincuente, mientras las criminologías del underclass abogan, más bien, por señalar la falta de autocontrol o de control social de individuos antisociales (2001: 177). 
En este esquema, hemos escuchado a oficiales jefe que centran las causas del delito en la provisión de asistencia social, de planes sociales, y sistemas de clientelismo político.

"S: ¿Cuáles crees que son las causas de los delitos?

B: $Y$, hay muchas, pero más que nada yo lo que veo es que falta compromiso de la gente, falta educación y hay mucho clientelismo, muchos planes mal dados.

S: ¿Por qué serían causas de delito esas?

B: Y... imagínate que se te acabó la plata de algún plan, entonces es más fácil robar una cartera que salir a laburar... más todavía si sos menor. Ahora dan planes entonces no se trabaja, así terminan acostumbrándose a la plata fácil y después tienen que salir a robar. Lo mismo, bueno la educación es obvio, ya no tienen los mismos valores" (Bernardo, comisario).

"S: ¿Por qué hay delito? ¿Cuáles son las causas del delito?

F: Mí criterio es por el gobierno. O sea, por los planes sociales. [...] Ahora el que viene si quiere estudiar estudia, si no quiere no estudia, total el gobierno me da planes, entonces viven el día. Ellos tienen pocos recursos y les gusta vivir así, ellos no tienen sentimiento de progresar" (Francisco, subcomisario).

En estos testimonios se pueden leer un determinismo tajante de la relación pobrezadelincuencia. Señalan, como núcleo del problema, en primer lugar a las políticas sociales de asistencialismo por parte del Estado. Pero a su vez, como apuntamos anteriormente, marcan al centro del problema como un acostumbramiento a la vivencia en situación de exclusión (4). El subcomisario Francisco lo expone manifestando que "les gusta vivir asi", esta afirmación ilustra la idea de la delincuencia como elección personal. Esto guarda relación con lo que exponen las teorías del underclass respecto al individualismo en la responsabilidad del delincuente.

Creemos que en estos extractos de entrevista se puede vislumbrar la idea que plantea Garland (2001), al señalar a las teorías del underclass como contrarias a aquellas welfaristas. Este caso también es el del subcomisario Raúl:

"Lo que yo veo es que hay mucha exclusión. Un sector de la sociedad que está muy excluido. De todo está excluido. De posibilidades, de ingreso a tener un buen trabajo, más allá del plan que cobran y la educación, que si ya no la tuvo no la va a tener. Vos decís, bueno, se van a escuela nocturna, pero ya estuvo preso antes. Ya pasó la época de que se tiene que formar la persona, y si ya se formó mal, ya está. Para mí, yo lo veo así" (Raúl, subcomisario). 
En esta cita, se puede encontrar una mixtura entre concepciones cercanas a las criminologías del penal-welfare, que predican a los procesos de socialización en general y, en particular, a los problemas de exclusión en diversos ámbitos; la educación, el ingreso al mundo del trabajo. Sin embargo, lo ubicamos cercano a las teorías del underclass ya que, nuevamente, señala a los planes sociales como agravantes de su situación, así como por la percepción sobre la irreversibilidad de la situación, tanto de pobreza, como de contacto y participación en prácticas delictuales. "De ahí no puede salir otra cosa", "Ya pasó la época" son aseveraciones condenatorias de una serie de condiciones socioculturales, marcando un determinismo lineal entre estas condiciones y la comisión de delitos.

El comisario Nicolás y el subcomisario Manuel, en este sentido, también remarcan aspectos cercanos a las teorías del underclass.

"Para mí la educación que viene de la casa, como base, es el mayor problema. Si en tu casa no tenés que tocar la pava porque está caliente es así, y todo parte desde ahí. No creo que una persona cambie" (Nicolás, subcomisario).

"Pasa que yo, trato de trabajar sobre los orígenes, prevención, en las escuelas, y el tema de la desinformación, y las pautas culturales atrofiadas, hacen que uno no se dé cuenta que está cometiendo un delito. [...] Ahora bien, qué tipo de educación puede llegar a una villa, ya está condenada. Las pautas socioeconómicas y culturales hacen a la facilidad de la sociedad en general" (Manuel, subcomisario).

Seguimos encontrando, en estos casos, una regularidad entre los entrevistados de pensar a la condición socioeconómica de los sectores populares como condicionantes de la propensión a delinquir. Casi como un aspecto de imposible o excepcional salida. Hallamos una propensión a delinear posibles escenarios familiares en la que los/as jóvenes que salen de ese núcleo familiar están condenados a dedicarse a la delincuencia. Como hemos visto, estos escenarios incluyen familias ausentes, presencia de prostitución, falta de educación, desobediencia, entre otros aspectos.

\section{La oportunidad hace al delito}

En este apartado nos abocamos a la presencia, entre los/as entrevistados/as, de formas de pensar la delincuencia como un cálculo, individual o grupal, estructurado, pensado, diagramado 
previamente, en función de determinadas condiciones. Esta manera de concebir al fenómeno criminal se relaciona con lo que Garland (2001) denomina criminologías de la vida cotidiana. El delito es así concebido como una oportunidad que se da y es aprovechada. Garland resalta, entonces, que esta forma de pensar a la criminalidad la retrata como una rutina más de la vida contemporánea (2001: 53), haciendo de éste un aspecto normal y habitual de la sociedad moderna, y separándolo así, de las teorías que incurren en patologizar al delito y al delincuente (2001: 217). El delito es visto así como un fenómeno que, dadas las mismas condiciones de riesgo-oportunidad, cualquiera podría haber aprovechado. El comisario Franco, entiende al delito casi estrictamente en estos términos.

"Pero un patrón, una tendencia, no te va a individualizar a ver "estos delitos, son tales personas". Porque el delito es un hecho individual. Que lo cometen... que para que se de, tienen que haber varias condiciones en el camino. Tiene que haber un lugar, tiene que haber una víctima, o un victimario. Tiene que haber una necesidad del victimario, la víctima no tiene que estar protegida, no tiene que tener un guardián" (Franco, comisario).

El foco para explicar la criminalidad está puesto en las condiciones. Al preguntar por las formas de pensar el delito, nos hemos encontrado con una gran cantidad de respuestas que apuntan a los problemas ambientales que habilitan la práctica, más que en las condiciones que hacen al delincuente. En esta tónica, resaltamos los testimonios de entrevistados que mencionan la aparición de estéreos en los autos, de motos más rápidas y del uso de celulares.

"El delito, el delito es una oportunidad que aparece para el delincuente. La sociedad va mutando, como lo ha hecho por su historia en un devenir de cosas. A través de esos cambios van apareciendo lugares, o momentos, donde... surge una posibilidad para el delincuente, ¿sí? para transgredir las normas. En su tiempo, no sé si vos recordas, aparecieron los autos con estéreo. Entonces se inició una posibilidad para las personas que quisieron vivir transgrediendo las normas, de apoderarse de los estéreos. La sociedad, las intervenciones policiales, las formas fue haciendo que esa innovación de la tecnología que tenía la sociedad, dejara de ser ya un blanco predilecto, porque ya no lo compraron más" (Franco, comisario).

"En ese momento todo lo de las motos era otra cosa, muy pocas personas podían tener moto. Y vos tenías los que tenían una motonetita, y después cuando tenían más plata ya tenían una Honda más cara más lujosa. Entonces los que robaban desde la moto eran seguro los que tenían las Honda, porque las otras motonetas no levantaban velocidad" (Lorenzo, comisario).

Question, Vol. 1, N. ${ }^{\circ}$ 63, julio-septiembre 2019. ISSN 1669-6581

Instituto de Investigaciones en Comunicación | Facultad de Periodismo y Comunicación Social | Universidad Nacional de La Plata 
"El delincuente trabaja con la sorpresa, apenas te dormís te agarran [...] Los celulares acrecentaron el delito, tenés el celular para todos lados, que es un aparato caro y chiquito entonces es fácil de robar" (Sergio, comisario).

"la aparición de tantas motos y celulares cambió todo. Hay mucho arrebato todo el tiempo. El delincuente chico era de ahí nomás antes. Antes el choro (5) era del mismo barrio donde delinquía. Ahora se fue a ocupar otros barrios" (Rodrigo, comisario).

Estos son ejemplos de cómo el delito es visto como una economía de condiciones necesarias para cometerlo. En los casos señalados la aparición del delito, así como su aumento o reducción, se encuentran condicionados por el entorno que lo habilita, o lo torna más riesgoso. El comisario Franco fue muy claro en su exposición: El delito es una oportunidad. Este es un núcleo para pensar las prácticas como guiadas por la elección racional. Dada una necesidad o un deseo particular, se evalúan racionalmente los medios para lograr un fin. Elster (1990) uno de los más grandes exponentes de la teoría de elección racional en sociología, explica que "Cuando enfrenta varios cursos de acción, la gente suele hacer lo que cree que es probable que tenga el mejor resultado" (Elster, 1990: 31). Siguiendo este planteo la acción es básicamente instrumental; las acciones son evaluadas, no por sí mismas, sino por la eficiencia que tienen para lograr otro fin, a partir de creencias y deseos propios (Elster, 1990).

Otro ejemplo de planteos cercanos a entender la criminalidad de este modo, lo da el subcomisario Francisco, que señala al descuido individual, como el mayor problema de seguridad.

"S: ¿Cuál crees que es el mayor problema de seguridad acá en Córdoba?

F: El descuido de la gente, la gente es muy descuidada, y sobre todo ustedes las mujeres. Pasa en mi familia. El hombre es más precavido porque está más atento, el varón. Hay algunos que no, pero el hombre te das cuenta. En cambio, la mujer, la mujer y los niños, si los ancianos son víctimas de todo porque con el estado físico que tienen, es obvio. Las mujeres tienen que tener la manía de decir, la cartera del otro lado, el celular acá" (Francisco, subcomisario).

En este caso el delito es considerado como una acción individual, motivada por otras acciones individuales. Señala al descuido de las víctimas en general, y de las mujeres en particular, como un factor que acrecienta la oportunidad de delinquir, y las hace, por tanto, responsables, 
no sólo de los delitos, sino también de los problemas de seguridad que hay en la ciudad. El descuido, aparece como un factor ambiental, que disminuye los costos del delito.

Este individualismo en la motivación para delinquir nos permite pensar un correlato con las criminologías del sí mismo. En el siguiente extracto de entrevista, el subcomisario Manuel destaca un elemento similar.

"S: ¿Crees que los delitos fueron cambiando con los años?

M: Mucho, todo. La motivación, la raíz siempre va a ser lo mismo, el placer. Siempre vas a querer estar mejor, entonces para conseguir ese placer va a variar las formas, pero el motivo es el mismo, estar mejor de lo que estas. Mejor casa, mejor auto" (Manuel, subcomisario).

Creemos que estos extractos son cercanos a uno de los aspectos que Garland expone respecto a las criminologías del sí mismo, y es que estas formas de representar el fenómeno criminal parten de la premisa de que el delito es un aspecto normal y habitual de la sociedad moderna. Por lo tanto, cometer un delito no requiere una motivación o disposición especial, una anormalidad o patología (Garland, 2001: 217), sino que aparece como una reacción normal o entendible. Nos acerca una idea de los fines del delincuente -de un delincuente universal-, como un objetivo económico para el cual han utilizado diversos medios -delictivos- con el paso del tiempo.

Encontramos, en estos como en otros relatos, una identificación del delito relacionado casi exclusivamente con aquellas faltas a la ley presentes entre los sectores populares; robos y "entraderas". Otros delitos, de cuello blanco, económicos a gran escala, por parte de élites económicas, no son apuntados más que marginalmente entre los/as entrevistados/as. Suponemos que esto responde a que las representaciones, como nos expone Bourdieu (2015), son una demostración de la relación práctica y táctica con las cosas del mundo (2015: 172). La mayoría de los/as oficiales jefes entrevistados/as desarrollan su actividad en áreas operativas, trabajando cotidianamente con estos tipos de delitos. Sus representaciones en torno a la delincuencia se ciernen así, en su mayoría, en relación a los delitos denunciados en las mismas comisarías, unidades judiciales, a través de llamadas telefónicas al sistema de emergencia 101, o toman conocimiento por la patrulla o reuniones vecinales.

\section{Algunas consideraciones sobre el bienestar}


Luego de las tres formas de concebir a la criminalidad que más encontramos entre los/as entrevistados/as resta por destacar las posiciones que piensan a la pobreza como un condicionante -no determinante- para la presencia de delito, pero plausible de ser rehabilitado. Los pocos fragmentos que se presentan aquí son aquellos cercanos a lo que Garland (2001) denomina criminologías de welfarismo penal.

Estas son formas de considerar que la raíz del delito estaba fuertemente concentrada en los sectores más pobres de la población, y en la relación entre pobreza, mala socialización y crimen (2001: 97). Las ideas criminológicas que moldearon la política pública durante el período de posguerra fueron una mezcla entre teorías psicológicas sobre anormalidad y teorías sociológicas como las de la anomia, la privación relativa, la subcultura y el etiquetamiento (2001: 51). En esta perspectiva "Los individuos se volvían delincuentes porque habían sido privados de una educación adecuada o de una socialización familiar o de oportunidades laborales o de un tratamiento adecuado de su disposición psicológica anormal" (Garland 2001: 53).

Entre los/as entrevistados/as encontramos algunas escasas alusiones respecto a la socialización defectuosa o inadecuada como causa del delito. Por un lado el comisario Rodrigo, nos habla de la falta de trabajo entre los jóvenes que delinquen:

"Te encontrás a las 10, 11 de la mañana a barritas de chicos que si estuvieran trabajando sería distinto. Con trabajo no pasa eso. El trabajo te mantiene la mente ocupada" (Rodrigo, comisario).

El reconocimiento del trabajo como algo que puede alejar a los jóvenes de la calle y mantenerlos ocupado se acerca, por lo menos, a una idea de rehabilitación. Toma al desempleo como un condicionante de la delincuencia, pero en este caso resalta que se puede revertir modificando esta condición. Retoma la idea de la junta, pero en este caso no es tajante su relación con el delito.

La comisario Daniela también nos da un ejemplo de esta forma de explicar la delincuencia. Ella lo explica a través de la asociación de los niños y jóvenes con los presos, o cacos más viejos.

"Cuando vienen acá al calabozo los convertís en resentidos por estar acá. Tenés el que no tenía nada que ver y se juntan con los cacos viejos que bue... [...] hay niños que por nada los llevaban y los haces vivir una situación tétrica. Cuando llegan vos ves cuándo tienen miedo y cuándo no. Así le arruinaron la vida a mucha gente" (Daniela, comisario). 
Estas explicaciones, con sus matices, ponen el acento en la idea de un sistema de valores que los hace propensos a cometer delitos, tanto dentro del hogar, como por fuera de él, con la junta. Como explica Kessler (2010), la noción de los grupos de pares, aparece frecuentemente en sociología, como una reacción e imprecisión de la teoría de la anomia de Merton. Esta última explica el delito como una tensión entre estructura social y valores culturales, en el cual las personas recurren a medios ilegítimos para lograr objetivos legitimados culturalmente por la sociedad. Sin embargo, el autor resalta que devino en una adjudicación de conductas desviadas a sujetos desviados y, casi por antonomasia, esos sujetos provenían de clases bajas (2010: 63).

Por este motivo es que las declaraciones en torno a la socialización defectuosa de los sectores populares se articulan con pensar la criminalidad desde las teorías del underclass. No obstante, los extractos que aquí vemos no son tan deterministas sobre la situación de pobreza para explicar la criminalidad como lo son aquellos destacados anteriormente. A su vez, destacan aspectos específicos sobre condiciones que favorecen la presencia de la criminalidad, sin manifestar una irreversibilidad.

\section{Reflexiones finales}

A lo largo del trabajo encontramos una serie de regularidades y singularidades a la hora de pensar la criminalidad y la prevención del delito entre los/as entrevistados/as. Lo primero a resaltar es que hemos encontrado una predominancia de pensar al delito como exclusivamente presente en las clases bajas. Esto se articula con la preeminencia entre los/as entrevistados/as, en pensar a la pobreza como un factor -no condicionante sino- determinante de la delincuencia. En estrecha articulación con esto, también abundaron, entre las entrevistas realizadas, las explicaciones del delincuente como un ser identificable a priori y como un enemigo público que la policía debe eliminar. Lo cual viene acompañado de una serie de arquetipos sobre apariencias físicas y hábitos culturales propios de sospechados de delinquir, y al olfato policial como una herramienta legítima para determinarlo. A su vez, identificamos una considerable cantidad de entrevistados/as que explican al delito y la criminalidad, de forma cercana a las teorías de elección racional, como una economía de las prácticas en la cual el delito aparece como una opción deseable.

Para cada una de estas formas de representar a la criminalidad, encontramos que hay oficiales jefes entrevistados/as que se encuentran en desacuerdo, así como unas pocas declaraciones en relación a pensar a la socialización defectuosa, la falta de trabajo y educación, como causal 
de delito. Sin embargo, cabe aclarar que estas últimas fueron accesorias en relación a las formas de pensar al crimen descritas anteriormente, y encontramos que terminan adjudicando conductas desviadas a sujetos desviados.

Esto indica, que encontramos una preeminencia, entre los/as entrevistados/as, de pensar al delito desde sus ópticas más tradicionales. Lejos de comprender al fenómeno de la criminalidad desde miradas más críticas, hallamos que la conflictividad es mayormente entendida como una desviación a un orden, un desequilibrio que se debe reprimir, en lugar de gestionar. La vulneración de derechos humanos y el carácter discriminatorio que esto puede tener, se agudiza aún más teniendo en cuenta que en la detección de un posible sospechoso se ponen a jugar las representaciones de la criminalidad desde las criminologías del otro y desde las concepciones de la pobreza como una underclass eminentemente delictual.

Por último, resaltamos que nos resulta clave entender estas concepciones entre aquellos que cotidianamente se relacionan con esta problemática, y trabajan en relación a ella, como son los oficiales jefes de la policía. Pero también, entender el "olfato social" que le da origen, y así revisar las representaciones en torno a la criminalidad que escuchamos cotidianamente.

\section{Notas}

(1) La expresión welfare, en inglés y tal como la usa el autor, hace referencia al conjunto de las intervenciones sobre la "cuestión social" estructuradas en el marco de una transformación de la forma de Estado producida desde fines del siglo XIX en diferentes contextos, con modalidades diversas, pero que se unifican en ciertos puntos básicos en la referencia al "welfare state" o "Estado de bienestar" (Garland, 2001).

(2) "Caco" es una forma coloquial de denominar a un ladrón.

(3) El artículo 111 del Código de convivencia ciudadana prohíbe transitar en moto sin patente, casco y documentos (artículo 111 de la Ley 10326 "Código de convivencia ciudadana de la provincia de Córdoba).

(4) Podríamos aseverar que hay una noción meritocrática de fondo en estas citas, partiendo también de la construcción de su lugar como policías, y como trabajadores que prescinden de programas de asistencia social.

(5) "Choro" es una forma coloquial de denominar a un ladrón.

\section{Bibliografía}


Bourdieu, P. (1990). Sociología y cultura. México: Ed. Grijalbo.

Bourdieu, P. (1999). La Miseria del mundo. Buenos Aires: Fondo de Cultura Económica.

Bourdieu, P. (2015). El sentido práctico. Buenos Aires: Siglo XXI Editores.

Brodeur, P. (2011). Las caras de la policía. Prácticas y percepciones. Buenos Aires: Prometeo.

Crisafulli, L. y Spósito, D. (2011). Por qué en Córdoba unos cuerpos valen más que otros. Racialismo y retórica oficial. En Crisafulli, L. y Bareto, I. L. ¡¿Cuánto falta?! CF, control social y Derechos Humanos. Córdoba, Argentina: INECIP.

Elster, J. (1990). Tuercas y tornillos. Una introducción a los conceptos básicos de las ciencias sociales. Barcelona: Gedisa.

Frederic, S. (2009). Comentario a "La dinámica de delito-policía en los procesos de reforma policial". En Kessler, G. (coord.). Seguridad y ciudadanía: nuevos paradigmas y políticas públicas. Buenos Aires: Edhasa.

Galvani, M. (2016). Cómo se construye un policía. La Federal desde adentro. Buenos Aires: Siglo Veintiuno Editores.

Garland, D. (2001). La cultura del control. Barcelona: Ed. Gedisa.

Kessler, G. (2010). Sociología del delito amateur. Buenos Aires: Paidós.

Kessler, G. y Dimarco, S. (2013). Jóvenes, policía y estigmatización territorial en la periferia de Buenos Aires. Espacio Abierto. Recuperado de http://www.redalyc.org/articulo.oa?id=12226914003

Kessler, G. (2011). El sentimiento de inseguridad. Sociología del temor al delito. Buenos Aires: Siglo XXI Editores.

Monjardet, D. (2010). Lo que hace la policía. Sociología de la fuerza pública. Buenos Aires: Prometeo.

Rodríguez Alzueta, E. (2014). Temor y control. La gestión de la inseguridad como forma de gobierno. Buenos Aires: Futuro Anterior Ediciones.

Suárez de Garay, M. E. (2016). Los policías: una averiguación antropológica Guadalajara. Jalisco: ITESO.

Sain, M. (2015). El Leviatán azul, Policía y política en la Argentina. Buenos Aires: Editorial Siglo $\mathrm{XXI}$.

Sozzo, M. (1999). ¿Hacia la Superación de la táctica de la sospecha? Notas sobre prevención del delito e institución policial. Recuperado de http://catedras.fsoc.uba.ar/diacsop/uploads/Sozzo-

Cels tactica\%20de\%20la\%20sospecha.pdf 
Wacquant, L. (2010). Castigar a los pobres. El gobierno neoliberal de la inseguridad social. Madrid: Gedisa. 